\title{
HIV-1/HIV-2 co-infection among voluntary counselling and testing subjects at a regional hospital in Cameroon
}

\author{
${ }^{*}$ Nsagha DS 1 , Njunda $\mathrm{AL}^{2}$, Kamga HLF², Assob JCN³ , Bongkem EA² \\ 1. Department of Public Health and Hygiene, Faculty of Health Sciences, University of Buea, Buea, Cameroon \\ 2. Department of Medical Laboratory Sciences, Faculty of Health Sciences, University of Buea, Buea, Cameroon \\ 3. Department of Biomedical Sciences, Faculty of Health Sciences, University of Buea, Buea, Cameroon
}

\begin{abstract}
Background: HIV/AIDS is a major public health problem in Cameroon which had a prevalence of 5.1\% in 2010 with 141 new infections per day. The fear of voluntary counseling and testing (VCT) is an obstacle to HIV prevention.

Objectives: To determine the prevalence of HIV-1, HIV-2 and HIV-1/HIV-2 co-infection among people attending a health facility for VCT.

Methods: Venous blood was collected from participants using aseptic techniques in a descriptive observational crosssectional study. DETERMINE HIV-1/2 and SD BIOLINE HIV-1/2 3.0 qualitative tests were used for the detection of HIV-1 and HIV-2 in their sera. Range and consistency checks were carried out on the data and analysed using Epi-Info.

Results: Of 290 individuals tested, 78(26.9\%) were positive for HIV-1 and HIV-2. Among the 78 HIV positive individuals, $62(79.5 \%)$ had HIV-1, 1(1.3\%) had HIV-2 and 15(19.2\%) had concurrent HIV-1/ HIV-2. Among those infected, 57(73.1\%) were females including $21(26.9 \%)$ males.

Conclusion: HIV-1 is the major cause of AIDS and VCT is well accepted. Co-infection with HIV-1/HIV-2 may lead to anti-retroviral drug resistance. VCT should be encouraged so that positive cases can initiate therapy on time to stay ahead of anti-retroviral drug resistance.

Keywords: HIV-1, HIV-2, HIV-1/HIV-2 co-infection, AIDS, sero-prevalence, voluntary counselling and testing; Cameroon African Health Sciences 2012; 12(3): 276 - 281 http://dx.doi.org/10.4314/ahs.v12i3.5
\end{abstract}

\section{Introduction}

HIV is a global health problem. In 2005, WHO and UNAIDS estimated that 40 million people were infected with HIV in the world; with more than 60\% of them in sub-Saharan Africa. The pandemic is dominated by HIV-1, which was discovered in 1983. In 1987, HIV-2 was discovered which is very common in West Africa ${ }^{1}$ and has not shown any significant spread from there. HIV-2 is less easily transmitted than HIV-1 and the period between initial infection and illness is longer than with HIV $-1^{2}$.

The prevalence of HIV in Cameroon was $5.1 \%$ in 2010 with significant regional variations ${ }^{3}, 141$

\section{*Correspondence author:}

Dr. Nsagha Dickson Shey

Department of Public Health and Hygiene

Faculty of Health Sciences

University of Buea

Box 63

Buea, Cameroon

Tel: (237) 77499429

Email:nsaghads@hotmail.com

dsnsagha@gmail.com new infections per day ${ }^{4}$ and transmission is mainly heterosexual $(90 \%)^{4}$. Part of the strategic response to HIV in Cameroon, has been the institutionalization of VCT for HIV services across the country ${ }^{5}$.

HIV-1 and HIV-2 co-infection in West Africa show $0.4 \% \mathrm{HIV}-1$ and $0.2 \% \mathrm{HIV}-2$ in northern Benin 6 , 6.6\% HIV-1 and 0.9\% HIV-2 in central Benin 7 , 25\% HIV-2 and 5\% HIV-1/HIV-2 in Mauritania ${ }^{8}$, 65\%HIV-1, 24\% HIV-2 and 11\% HIV-1/HIV-2 in Senegal ${ }^{9}$ and $12.1 \%$ HIV-1, $0.5 \% \mathrm{HIV}-2$ and $1.6 \%$ co-infection in north western Nigeria ${ }^{10}$.

HIV-1/HIV-2 co-infection studies revealed a difference in the progression to AIDS among HIV1, HIV-2 or co-infection and their response to antiretrovirals ${ }^{2}$. There are three categories of antiretrovirals ${ }^{2}$ : nucleoside reverse transcriptase inhibitors (NsRTIs) (zidovudine, didanosine, stavudine, lamivudine, abacavir, zalcitabine, and emtricitabine); non-nucleoside reverse transcriptase inhibitors (NNRTIs) (nevirapine, efavirenz, delavirdine) and nucleotide reverse transcriptase inhibitors like tenofovir ${ }^{2}$. The protease inhibitors 
include saquinavir, ritonavir, indinavir, nelfinavir, lopinavir/ritonavir, amprenavir, and atazanavir. A combination of at least three antiretrovirals, usually two NsRTIs and a NNRTI are recommended for continued effectiveness and to prevent the emergence of drug-resistant HIV strains ${ }^{2}$.

In many countries, HIV remains a highly stigmatizing condition and there are many anecdotal reports of people being stigmatized for being seropositive. This is common when people are tested mandatorily or without adequate counseling ${ }^{11,12}$. As the HIV/AIDS pandemic advances, VCT should be provided along with sensitisation ${ }^{13}$. VCT is important in improving care and support ${ }^{14}$ and many developing countries are instituting it as part of the primary health care package ${ }^{15}$. Developments in cotrimoxazole prophylaxis ${ }^{16,17}$ and tuberculosis preventive therapies ${ }^{18}$ for HIV people, antiretroviral (ARV) therapy ${ }^{19}$ and PMTCT ${ }^{20}$, have expanded to VCT. This study was conducted to determine the HIV prevalence and its major strains (HIV-1 andHIV2) in people coming for VCT in a regional hospital setting.

\section{Methods}

\section{Study Area}

This study took place in Buea, the headquarters of the South West Region of Cameroon. There are many ethnic groups in Buea including the Bakweri (indigenes), Bamileke, Bafou, Balondu, Metta and Bayangi among others. Buea has a population of about 200.000 inhabitants and is located $15 \mathrm{kms}$ from the Atlantic Ocean, and 60 kilometres from Douala, the economic capital of Cameroon. Most inhabitants practice agriculture as the main economic activity. Buea has two seasons: the dry season from October to March and the wet season from March to September. Almost all ethnic groups in Cameroon are represented in Buea, attracted by the fertile volcanic soil and the Cameroon Development Corporation, a giant agricultural corporation that seconds the state of Cameroon in employment.

\section{Study design and setting}

The design was a descriptive observational crosssectional hospital-based study in a tertiary health care facility in Buea, Cameroon. The Buea Regional Hospital Annex(BRHA) has thirteen services: administration, paediatric, surgery, maternity, theatre, $\mathrm{x}$-ray, laboratory, dental, diabetes unit, tuberculosis unit, eye unit, family planning, outpatient, HIV/AIDS unit, the male and female medical units.

\section{Study population and sample size}

The study population involved males and females of different age groups who came to the BRHA for VCT from October $27^{\text {th }}$-December $16^{\text {th }} 2009$. Samples were collected after due counselling and informed consent from all individuals at the HIV/ AIDS counselling unit of the hospital. Only those that consented to VCT were included in the study. 290 samples were collected from all individuals presented for VCT during the study period.

The authorization to carry out this study was obtained from the Faculty of Health Sciences, University of Buea. Ethical clearance was obtained from the Regional Delegation of Public Health, Buea. Informed consent was obtained from all persons before any information and blood sample were collected.

\section{Specimen collection and laboratory analysis}

Venous blood was collected by venepuncture using aseptic techniques. About $3-4 \mathrm{ml}$ blood samples was transferred into a labelled dry tube, centrifuged at $3000 \mathrm{rpm}$ for 5 minutes to separate serum from red cells, labelled and stored between $2-8^{\circ} \mathrm{C}$. Serum samples were analysed using two qualitative tests: DETERMINE HIV-1/2 and SDBIOLINE-1/2 3.0.

\section{Laboratory procedures for the immunochromatographic tests}

We used DETERMINE HIV-1/2 to detect all the positive samples and SD BIOLINE HIV-1/2 3.0 to identify HIV-1, HIV-2, and HIV-1/HIV-2. The tests were performed using the WHO Bulk Procurement Scheme for HIV Assays ${ }^{21}$.

For DETERMINE, 10-test cards were removed and the strips placed on a table. Using a clean micropipette, $50 \mu \mathrm{l}$ serum was applied to the pad. All samples were tested with new strips from the same lot number. Results were read between 1560 minutes. To insure assay validity, a procedural control was incorporated. When the control bar did not turn red upon assay completion, the test result was invalid and the sample retested. Red bars appearing in both the control and patient windows were interpreted as positive. Any visible red colour in the patient window was interpreted as positive. One red bar in the control window with no red bar in the patient window was interpreted as negative. When there was no red bar in the control window, even if a red bar appeared in the patient window, the result was invalid and repeated. 
For BIOLINE, the test kit was removed, and placed on a table. Using a micropipette, $20 \mu \mathrm{l}$ of serum was added into the well. Four drops of assay diluent were added and results read in 5-20 minutes. The presence of only a control line within the result window indicated a negative test. The presence of two lines as control line and test line 1 within the result window indicated a positive HIV1. The presence of two lines as control line and test line 2 within the result window indicated a positive HIV-2. The presence of three lines as control, test line 1 and test line 2 within the result window indicated a positive HIV-1/HIV-2. When the colour intensity of test line 1 was markedly darker than that of test line 2 in the result window, it was interpreted as HIV-1. When the colour intensity of test line 2 was markedly darker than that of test line 1 in the result window, it was interpreted as HIV-2. When colour intensities of test lines 1 and 2 in the result window were the same, it was interpreted as HIV-
1/HIV-2. The results were entered into a log book and analyzed using Epi-Info after a double entry by two data clerks.

\section{Results}

The ages ranged from 1-77 years, the mean was 30.5+10.96. Of the 290 samples tested, 78(26.9\%) were positive with DETERMINE HIV-1/2. Among the 78 positive cases, there were $57(73.1 \%)$ females and $21(26.9 \%)$ males $(\mathrm{P}>0.70)$ (table 1). Of the 78 positive cases tested with SD BIOLINE HIV-1/2, $62(79.5 \%)$ were HIV-1, 1(1.3\%) HIV-2, and 15(19.2\%) HIV-1/ HIV-2 (table 2). For those who were HIV-1/HIV-2 co-infected, they were $13(86.7 \%)$ females and $2(13.3 \%)$ males. The coinfection was among the residents of Buea Health District. No data on profession, religion, educational level, health area and the tribe of the participants was collected in this study.

Table 1: Overall HIV sero-prevalence in the study population

\begin{tabular}{llll}
\hline HIV sero-status & $\begin{array}{l}\text { Males } \\
\text { No (\%) }\end{array}$ & $\begin{array}{l}\text { Females } \\
\text { No (\%) }\end{array}$ & $\begin{array}{l}\text { Total } \\
\text { No (\%) }\end{array}$ \\
\hline Number of positive cases & $21(26.9)$ & $57(73.1)$ & $78(26.9)$ \\
Number of negative cases & $59(27.8)$ & $153(72.2)$ & $212(73.1)$ \\
Total & $\mathbf{8 0 ( 2 7 . 6 )}$ & $\mathbf{2 1 0 ( 7 2 . 4 )}$ & $\mathbf{2 9 0 ( 1 0 0 . 0 )}$
\end{tabular}

$\mathrm{X}^{2}=0.07, \mathrm{P}>0.70$

Table 2: Seropositivity of the different sub-types of HIV infection among the seroprevalence cases and according to gender

\begin{tabular}{lccc}
\hline HIV sero-status & $\begin{array}{l}\text { Males } \\
\text { No (\%) }\end{array}$ & $\begin{array}{l}\text { Females } \\
\text { No (\%) }\end{array}$ & $\begin{array}{l}\text { Total } \\
\text { No (\%) }\end{array}$ \\
\hline $\begin{array}{l}\text { Number of HIV-1 positive } \\
\text { cases }\end{array}$ & $19(30.6)$ & $43(69.4)$ & $62(79.5)$ \\
$\begin{array}{l}\text { Number of HIV-2 positive } \\
\text { cases }\end{array}$ & $0(0.0)$ & $1(100.0)$ & $1(0.4)$ \\
$\begin{array}{l}\text { Number of HIV-1/ HIV-2 } \\
\text { Co-infection cases }\end{array}$ & $2(13.3)$ & $13(86.7)$ & $15(19.2)$ \\
Total & $\mathbf{2 1 ( 2 6 . 9 )}$ & $\mathbf{5 7 ( 7 3 . 1 )}$ & $\mathbf{7 8 ( 1 0 0 )}$ \\
\hline
\end{tabular}

$\mathrm{X}^{2}=2.21, \mathrm{P}>0.30$

Among the HIV positive cases, the infection was more prevalent in the age groups of 20-29 and 3039 , with a $30.8 \%$ HIV prevalence; the mean age was 29.5 years (table 3 ). There was no significant difference in the distribution of HIV in the different age groups $(\mathrm{p}=0.41)$. 
Table 3: HIV seropositivity according to age and gender among the seroprevalence cases

\begin{tabular}{|c|c|c|c|c|c|c|c|c|}
\hline \multirow[t]{2}{*}{ Gender } & \multicolumn{8}{|c|}{ Age group(years) } \\
\hline & $\begin{array}{l}\leq 9 \\
\text { n }(\%)\end{array}$ & $\begin{array}{l}10-19 \\
\text { n }(\%)\end{array}$ & $\begin{array}{l}20-29 \\
\text { n }(\%)\end{array}$ & $\begin{array}{l}30-39 \\
\text { n }(\%)\end{array}$ & $\begin{array}{l}40-49 \\
\text { n }(\%)\end{array}$ & $\begin{array}{l}50-59 \\
\text { n }(\%)\end{array}$ & $\begin{array}{c}\geq 60 \\
\text { n }(\%)\end{array}$ & $\begin{array}{l}\text { Total } \\
\text { n }(\%)\end{array}$ \\
\hline $\begin{array}{l}\text { Number of } \\
\text { positive males }\end{array}$ & $1(4.8)$ & $1(4.8)$ & $2(9.5)$ & $6(28.6)$ & $8(38.1)$ & $3(14.3)$ & $0(0.0)$ & $21(27.0)$ \\
\hline $\begin{array}{l}\text { Number of } \\
\text { positive females }\end{array}$ & $0(0.0)$ & $2(3.5)$ & $22(38.6)$ & 18(31.6) & $10(17.5)$ & $4(7.0)$ & $1(1.8)$ & $57(73.0)$ \\
\hline Total & $1(1.3)$ & $3(3.8)$ & $24(30.8)$ & $24(30.8)$ & $18(23.1)$ & $7(9.0)$ & 1(1.3) & $78(100)$ \\
\hline
\end{tabular}

$\mathrm{X}^{2}=11.1, \mathrm{P}>0.05$

\section{Discussion}

The HIV-1/HIV-2 co-infection has treatment implications because nonnucleoside reverse transcriptase inhibitors, crucial in standard first-line regimens for HIV-1 in many low-income settings [like Cameroon], has no effect on $\mathrm{HIV}-2^{22}$. Nucleoside analogues alone are not sufficiently potent enough to achieve durable virologic control. Some protease inhibitors without ritonavir boosting are not sufficiently effective against HIV-222.

The most crucial difference between HIV1 and HIV-2 when considering suitable antiretroviral regimes is the lack of susceptibility of the firstgeneration NNRTIs, nevirapine, and efavirenz $z^{22}$. The natural resistance of HIV-2 to these drugs is due to differences in the amino acid residues that make contact with the NNRTI in the binding pocket of HIV-1 and HIV-2, particularly the Y181I and Y188L natural polymorphisms seen in HIV-2, which significantly reduce NNRTI binding ${ }^{22}$. HIV-1 mutations at these positions result in complete resistance to NNRTIs. Although etravirine has more activity against HIV-2 than previous NNRTIs, the presence of L181 and other structural differences in the HIV-2 NNRTI-pocket make HIV-2 naturally resistant to etravirine ${ }^{22}$

The lack of susceptibility of HIV-2 to NNRTIs indicate that patients with co-infection need to use an adapted combination to suit their condition, adding a second- line treatment regime to the standard first-line for HIV-1 infection ${ }^{22}$. Second line therapy ideally include a minimum of three new drugs, with at least one from a new class, in order to increase treatment success. The implications are that patients have to spend more on testing and buying $\operatorname{drugs}^{22}$. This means that government policy on HIV treatment has to change occasionally whenever there is any documented resistance to treatment regimes when HIV-2 is diagnosed due to viral natural polymorphism ${ }^{22}$.
In this study, there were more HIV-1 than HIV-2 which contrasts the findings of a Malian study ${ }^{23}$ where there were more HIV-2 than HIV-1. This study agrees with the work of Abdulazeez et $a^{10}$, who found $12.1 \%, 0.5 \%$ and $1.6 \%$ for HIV-1, HIV-2 and HIV-1/HIV-2 respectively but different from that of Ndiaye et al . The increase in HIV-1/ HIV-2 co-infection in our study and that of Abdulazeez et al ${ }^{10}$, suggests that there may be more co-infection with the two virus strains.

The $26.9 \%$ HIV seroprevalence was significantly high in the population as compared to the $5.3 \%$ prevalence in the Cameroonian population ${ }^{24}$. The presence of many higher institutions of learning in Buea increases the youth population who are more vulnerable because of their sexual habits.

VCT constitute a major component of the UNAIDS 2011-2015 strategic plan of "three-zeros" - zero new infections, zero stigma and zero deaths ${ }^{25}$. VCT is important for HIV prevention in communities with generalised epidemics like Cameroon. It allows adolescents to know their HIV status and to evaluate their behaviour and its consequences while a negative test reinforces the importance of safe and risk-reducing behaviours. VCT benefits include improved health status, emotional support, better coping ability, PMTCT feeding awareness options, motivation to initiate or maintain safer sexual and drug-related behaviors, and safer blood donation ${ }^{26}$. Stigma may actively prevent people accessing care, gaining support, and preventing onward transmission. Hence, UNAIDS ${ }^{24}$ stipulated that testing should be voluntary, and VCT should take place in collaboration with stigmareducing activities ${ }^{26}$.

The International Guidelines on HIV/AIDS and Human Rights ${ }^{27}$ advises against mandatory HIV testing for both public health and human rights reasons. The World Health Assembly ${ }^{28}$ resolved that 
there was no public health rationale for measures establishing mandatory HIV screening ${ }^{26}$.

Our findings showed that the most infected were in the 20-29 and 30-39 age brackets which agrees with results of UNAIDS ${ }^{29}$, that the HIV prevalence in Cameroon is more amongst people aged 15-49 years. There was no significant difference in HIV infection with age and sex $(p>0.05)$; hence both males and females of all age groups have the same likelihood of being infected with HIV.

During the early years of HIV infection in Cameroon, social stigma was very high and treatment was not easily available ${ }^{30}$. With the availability of free HIV/AIDS drugs ${ }^{26}$, many people are willing to go for VCT and treatment.

We could not obtain some demographic information from participants because of logistic reasons. Cost problems of conducting VCT, psychological trauma and stigma are inherent in our environment.

\section{Conclusion}

We had a prevalence of $26.9 \%$ for HIV-1 and HIV2, 62(79.5\%) for HIV-1, 1(1.3\%) for HIV-2 and 15(19.2\%) for HIV-1/ HIV-2. There were 57(73.1\%) females and $21(20.9 \%)$ males infected giving a ratio of 3:1. HIV-1 is the major cause of AIDS and VCT is well accepted. HIV-1/HIV-2 co-infection may lead to anti-retroviral resistance. HIV screening in Cameroon should test for co-infection; anti-retroviral resistance should be investigated in Buea.

\section{Acknowledgements}

We thank all the participants who gave their consent and donated their blood. We are grateful to the Director of BRHA, Dr. Victor Mbome Njie for the permission, the nurses and the laboratory staff for their co-operation in data collection and analysis.

\section{Conflict of interest}

This work has no conflict of interest to declare.

\section{References}

1. Eholie S and Anglaret X. Decline of HIV-2 prevalence in West Africa: Good news or bad news? International Journal of Epidemiology 2006; 35(5):1329-1330.

2. Cheesbrough M. Human immunodeficiency virus (HIV). District Laboratory Practice in Tropical Countries. Part 2, Second Edition. Cambridge University Press. 2006; 253-265.
3. Ministry of Public Health. National AIDS Control Committee. Annual Report, Cameroon.2004.

4. Mbanya D, Sama M and Tchounwou P. Current status of HIV/AIDS in Cameroon: How effective are control strategies? International Journal of Environmental Research and Public Health 2008; 5(5): 378-383.

5. Ngwakongnwi E \& Quan H. Sex differentials in the use of centres for voluntary counselling and testing for HIV in Cameroon. African Journal of AIDS Research 2009; 8(1): 43-49.

6. Zanchette N, Vigano P, Priuli GB, Ferrario MP, Zago M, Pagano A. HIV-1 and HIV-2 prevalence of seropositivity in a population of Western Africa. European Journal of Epidemiology 1990; 6(1): 71-75.

7. Chippaux JP, Maillot L, Castel J, Bochet B, Massougbodji A, Zohoun T et al. Prevalence of HIV-1 and HIV-2 antibodies in rural areas of Benin. Bulletin de Societé de Pathologie Exotique 1990; 83(4): 437-45.

8. Baidy Lo B, Adimorty M, Fatimata C, Amadou S. Surveillance of HIV seroprevalence in Mauritania. Bulletin de Societé de Pathologie Exotique 1993; 86(2):133-135.

9. Ndiaye P, Diedhiou A, Ly D, Fall C, Tal-Dia A. HIV/AIDS Prevalence among the attendees at the center for voluntary and anonymous detection and support in Pekine/Guediawaye, Senegal. Medicin Tropicale 2008; 68(3): 277-82.

10. Abdulazeez A, Alo E, and Naphthali R. Concurrent infection of HIV-1 and HIV-2 serotypes in Adamawa State Nigeria. World Journal of Medical Science 2008; 3(1): 15-18.

11. Maman S, Mbwambo J, Hogan M. History of partner violence is common among women attending a voluntary counseling and testing clinic in Dar Es Salaam, Tanzania. 13th International Conference on HIV/AIDS. Durban, South Africa. 2000.

12. Keogh P, Allen S, Almedal C, Temahagili B. The social impact of HIV infection on women in Kigali, Rwanda: a prospective study. Social Science and Medicine 1994; 38(8): 1047-53.

13. UNICEF. Cameroon: HIV/AIDS. Available at: http://www.unicef.org/infobycountry/ cameroon_statistics.html. 2009. Accessed 23 October 2011. 
14. UNAIDS. The impact of Voluntary counseling and testing: A global review of the benefits and challenges. Available at: http://www.unaids.org. 2001. Accessed May 272006.

15. Coovadia $\mathrm{H}$. Access to voluntary counseling and testing for HIV in developing countries. Annals of the New York Academy of Science 2000; 918(2000): 57-63.

16. Wiktor SZ, Sassan-Morokro MS, Grant AD, Abouya L,Karon JM, Maurice C, et al. Efficacy of trimethoprim-sulphamethoxazole prophylaxis to decrease morbidity and mortality in HIV-1 infected patients with tuberculosis in Abidjan, Côte d'Ivoire: a randomized controlled trial. The Lancet 1999; 353(9163): 1469-1475.

17. Anglaret X, Chene G, Attia A, Toure S, Lafont $\mathrm{S}$, Combe P, et al. Early chemoprohylaxis with trimethoprim- sulphamethoxazole for HIV-1 infected adults in Abidjan, Côte d'Ivoire: a randomized controlled trial. The Lancet 1999; 353(9163): 1463-1468.

18. Mwingwa A, Hosp M, \& Godfrey-Faussett P. Twice weekly tuberculosis preventive therapy in HIV infection in Zambia. AIDS 1998; 12(18): 2447-2457.

19. Carpenter C, Cooper A, Fischl M. Antiretroviral therapy in adults. Updated recommendations of the International AIDS society - USA panel. Journal of American Medical Association 2000; 283(3): 381-390.

20. Shaffer N, Chuachoowong R, Mock PA, Bhadrakom C, Siriwasin W, Young NL et al. Short-course zidovudine for perinatal HIV-1 transmission in Bangkok, Thailand: a randomised controlled trial. Lancet 1999; 353(9155): 773-80.

21. WHO Bulk Procurement Scheme.HIV Assays: Operational characteristics. Available at: http:/ / www.who.int/diagnostics-laboratory/ publications/Report16_final.pdf. 2005. Accessed 3 November 2011.
22. 22. Kevin P, Sabelle J, Sarah LR, and Thushan IS. Antiretroviral Therapy for HIV-2 Infection: Recommendations for Management in LowResource Settings. AIDS Research and Treatment 2011; Article ID 463704, 11 pages. doi:10.1155/2011/463704

23. Maiga MY, Diarra B, Guindo A, Maiga YI, Fofano O, Bougoudogo F. Seroprevalence of HIV in Mali on 3496 sera. Bulletin de la Societé de Pathologie Exotique 1993 ; 86(1): 16-20.

24. UNAIDS. Report on the Global AIDS Epidemic 2010. Available at: http:// www.unaids.org/globalreport/documents/ 20101123_GlobalReport_full_en.pdf.2010. Accessed 08 April 2011.

25. UNAIDS. 2011-2015 Strategy Getting to zero. Available at: http://www.unaids.org/en/media/ unaids/contentassets/documents/ un a i d s publication/2010/ JC2034_UNAIDS_Strategy_en.pdf. 2011. Accessed 16 December 2011.

26. Baggaley R. Voluntary counselling and testing. Paper for the UNAIDS expert panel on HIV testing in United Nations peacekeeping operations. 17-18 ${ }^{\text {th }}$ September 2001, New York. Pages 1-23.

27. UNAIDS and the Office of the UN High Commissioner for Human Rights. The International Guidelines on HIV/AIDS and Human Rights. Available at: http:// www.unaids.org. 1998. Accessed September 10 2010.

28. WHO. Testing HIV policy. Resolution WHA 45.35, 14 May 1992. Available at: bttp:// wnw. hivpolicy.org/Library/HPP000109.pdf. 1992. Accessed 20 February 2010.

29. UNAIDS. AIDS epidemic update. Available at: http://www.unaids.org. 2009. Accessed March 192009.

30. Eboko F. Evaluation of the access to ART and the health care system in Cameroon. Presentation at the WHO meeting on positive synergies between health systems and global health initiatives. 2-3 October 2008, Marseille, France. 